\title{
Precordial low-frequency displacements of the thoracic wall . Method of recording and registration
}

\author{
H. Schneider, M.Sc. \\ E. W. J. M. Klunhaar, M.D. \\ Utrecht, Netherlands
}

$\mathrm{T}$ The recording and registration of lowfrequency precordial movements of the chest wall caused by cardiac action have become the focus of increasing attention in the past few decades. In this connection, we may refer to publications by Johnston and Overy, ${ }^{6}$ in which is presented a survey of results obtained up to 1951, with their interpretation.

Continuing this line of investigation, Eddleman, ${ }^{8-10,12}$ Luisada, ${ }^{7}$ Groom and Elliott, ${ }^{11}$ with their respective co-workers, have developed recording methods which have contributed to our knowledge of precordial movements of the chest wall. For this purpose, Eddleman made use of the fact that mechanical fluctuations in pressure can be piezoelectrically converted into electrical signals. Luisada recorded precordial movements of the chest wall with the aid of a contact crystal microphone. Groom used the electronic pick-up RCA 5734-the triode with the moving anode. Ellioll used the acceleroneter, based on the principle of electrocapillarity.

For the same purpose, we have used the Philips displacement meter and transducer. based on the principle of the differential transformer.

\section{Method}

If mechanical quantities are measured by electrical methods, then the apparatus required can be divided into two parts, i.e., (a) the transducer, with which the mechanical quantity is converted into an electrical quantity, and (b) the measuring apparatus, with which the electrical quantity is amplified and measured.

The transducer. The transducer PR 9310/ 01 is an instrument with a length of 5.3 $\mathrm{cm}$. and a diameter of $2.3 \mathrm{~cm}$. (transverse section shown in Fig. 1). It consists of a steel casing $(A)$ with a copper lining $(B)$, from which a needle $(K)$ protrudes; we fixed a globule of resin $(E)$ with a diameter of $1 \mathrm{~mm}$. onto the end of this protruding needle. The center of the needle contains a small ferromagnetic core $(H)$. Both the needle and the core are movable in axial direction in a tube (not magnetizable within the steel casing) on which one primary $(C)$ and two secondary coils $(G)$ have beerl mounted.

The axial movement of the core of the measuring needle results in a change in the coupling of each of the two secondary coils with the primary coil; as a result, the voltages induced in the secondary coils

From the Department of Medical Physics and the Department of Cardiology, University Hospital of Utrecht, Utrecht, Netherlands.

Received for publication Oct. 20,1960 . 


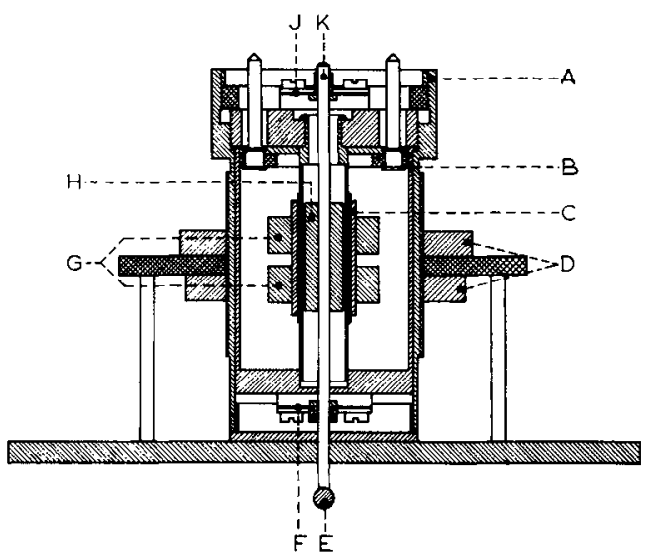

Fig. 1. Transverse section of the transducer and plastic holder $(\phi 6 \mathrm{~cm}$.

are opposed. The ensuing difference in voltage can be determined with the aid of a suitable measuring apparatus, connected with the transducer by means of a measuring cable, $5 \mathrm{M}$. in length.

The coil system of the transducer is electrically screened off by means of the copper lining inside the steel casing. The induced voltages, therefore, are not influenced either by the metal holder into which the instrument may be built or by static fields in the vicinity.

The primary coil is fed a stabilized al- ternating current $(2.75$ volts effective at $30 \mathrm{Ma}$., 4,000 Herz.).

With the aid of adjusting nuts $(D)$, the entire system was mounted in an adjustable plastic holder ( $\phi 6 \mathrm{~cm}$.) which can be attached to the patient by means of a rubber band, so that the measuring needle can be applied to any desired site on the thorax. In this way, the investigator's interference with registration, as well as the influence of respiration, are avoided, as are also minor displacements of the patient relative to a transducer not attached to the patient. The displacement of the rim of the holder is small in comparison to the displacement of the probe.

The mass of the moving system amounts to 1 gram, and this implies that the influence on the object to be measured is inconsiderable. The measuring needle of the transducer is subject to outward pressure exerted by bearing springs $(F, J)$, with a force which amounts to about $2 \times 10^{4}$ dynes in the central position. The spring rigidity is $15 \times 10^{4}$ dynes per centimeter. During use, the measuring needle must not be subjected to transverse stress, i.e., stress perpendicular to the longitudinal axis.

The maximal deflection, i.e., the permissible deflection longitudinally to either side

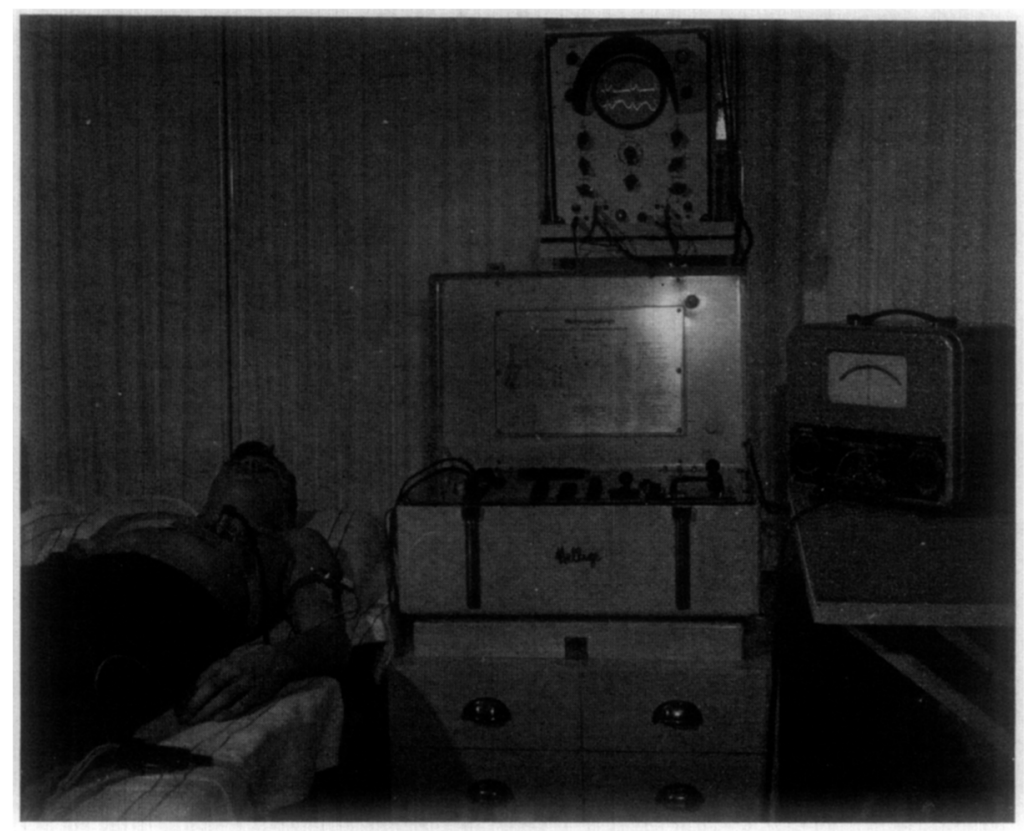

Fig. 2. Left: Transducer fixed on the patient. Center: Hellige recorder and the cathode-ray tube. Right: Measuring apparatus. 


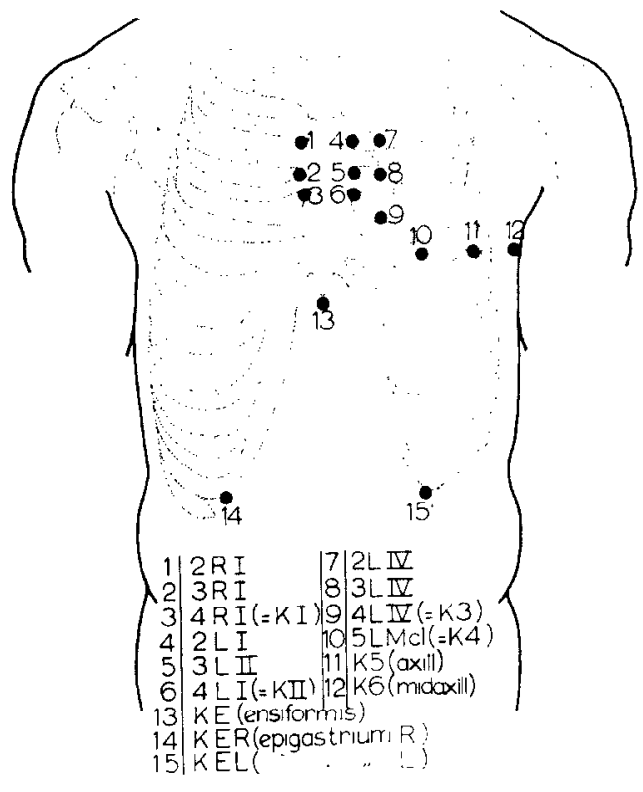

Fig. 3. See text.

of the central position of the measuring needle, is $1 \mathrm{~mm}$. Overloading of the measuring apparatus occurs after larger displacements of the chest wall. The apparatus is capable of measuring, independently, vibrations ranging from frequency 0 cycles per second to frequency 70 cycles per second (independent of amplitude); a reproducible and proportionate recording of the displacement of the chest wall is thus ensured. The sensitivity is $0.25 \mathrm{mv} . / \mu \mathrm{m}$.

It should be pointed out that the output voltage emitted is proportionate to the displacement instead of to the velocity, as in the case of electromagnetic and electrodynamic recorders.

The measuring apparatus. The measuring bridge, which can be regarded as a bridge of wheatstone, is the most important part of the measuring apparatus (PR 9300).* This bridge, combined with the transducer described in the previous section, makes it possible to measure the displacements of the measuring needle.

It is possible to adjust the apparatus to the following six measuring ranges, which differ by a factor of 3 : from +3 to $-3 \mu \mathrm{m}$; +10 to $-10 \mu \mathrm{m} ;+30$ to $-30 \mu \mathrm{m} ;+100$ to $-100 \mu \mathrm{m} ;+300$ to $-300 \mu \mathrm{m} ;+1,000$ to $-1,000 \mu \mathrm{m}$.

The values for slow fluctuations of the chest wall, e.g., due to respiration, can be *PR $9300=$ Serial number of Philips Electronics. read directly from a dial instrument continuous-current microamperemeter with $\mathbf{5 0 0}$ microamperes at full dial deflection). In our experiments, this instrument was used only for orientation as to measuring limits.

After adjustment, observations were made with the aid of a cathode-ray tube for visual evaluation, and the recording with a four-channel photographic Hellige apparatus. The output of the measuring apparatus, it was found, could be readily adapted to the final stage of the above-mentioned Hellige apparatus. Recordings were made synchronously with heart sounds and electrocardiographic findings.

If desirable, a segment of the displacement curve with high sensitivity can be studied in detail while the remainder of the curve is overloaded.

Application to the patient. The abovedescribed apparatus is set up, and the transducer attached to the chest of the

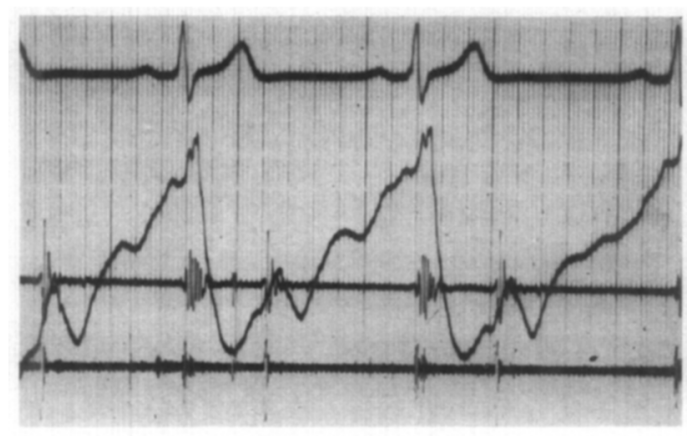

Fig. 4. Kinetocardiogram: $(2 \mathrm{R} 1)=\mathrm{K}_{12}$. Measuring range: $+10 \mu \mathrm{m}$ to $-10 \mu \mathrm{m}$. ECG: Lead II. Phonocardiogram: Apical sounds. Speed of paper: $50 \mathrm{~mm}$. per second.

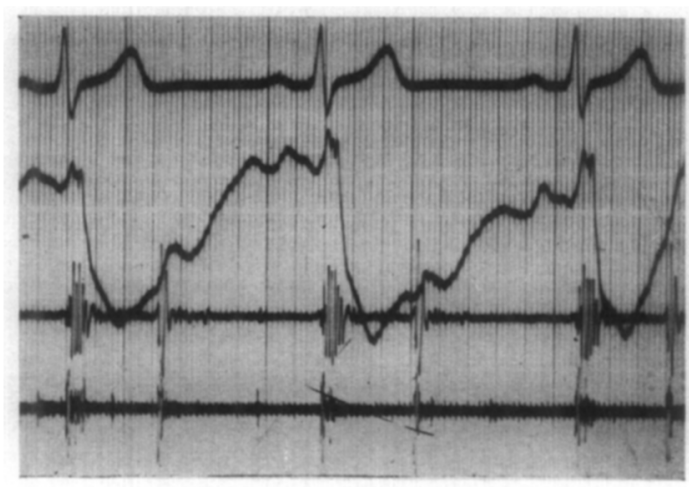

Fig. 5. Kinetocardiogram: $(3 \mathrm{R} 1)=\mathrm{K}_{13}$. Measuring range, ECG, phonocardiogram, and paper speed are the same as for Fig. 4. 


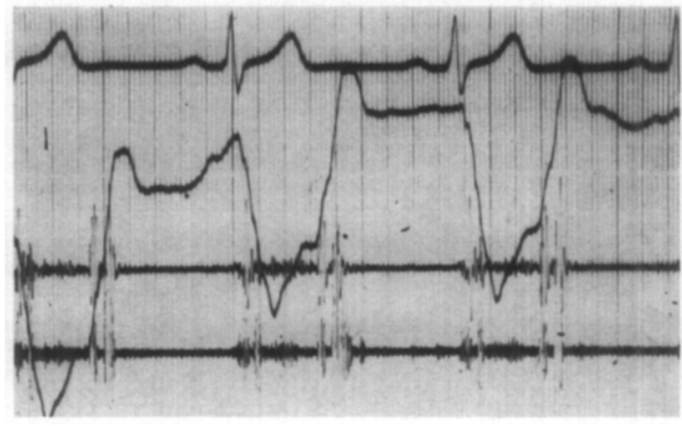

Fig. 6. Kinetocardiogram: $(4 \mathrm{R} 1)=\mathrm{K}_{14}$. Phonocardiogram: Sounds 2L1. Measuring range, ECG, and paper speed are the same as for Fig. 4.

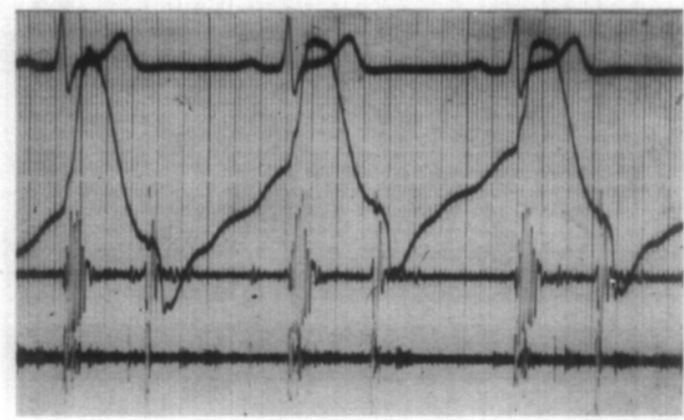

Fig. 7. Kinetocardiogram: $(2 \mathrm{~L} 1)=\mathrm{K}_{22}$. Measuring range: $+30 \mu \mathrm{m}$ to $-30 \mu \mathrm{m}$. ECG: Lead II. Phonocardiogram: Apical sounds. Speed of paper: $50 \mathrm{~mm}$. per second.

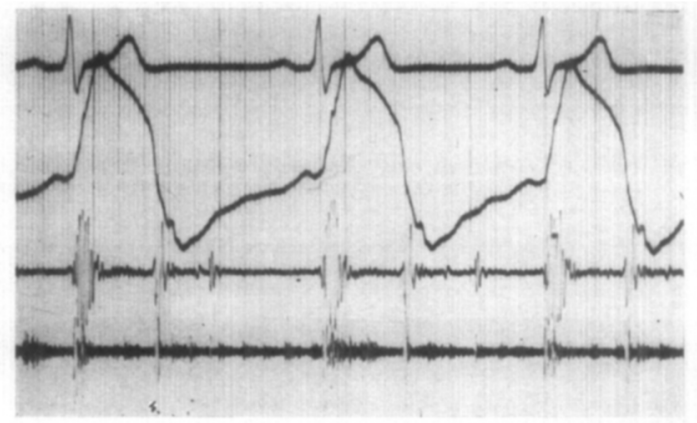

Fig. 8. Kinetocardiogram: $(3 \mathrm{~L} 1)=\mathrm{K}_{ \pm 3}$. Measuring range, ECG, phonocardiogram, and paper speed are the same as for Fig. 7 .

subject under examination, in the manner demonstrated in Fig. 2. It is ascertained that the measuring needle of the transducer is localized at the exact site on the chest wall at which precordial movements are to be measured; the transducer with the measuring needle can be shifted in the holder (by means of a fine-pitched screw thread) in such a way that the measuring needle itself is in the central position perpendicular to the chest wall. This last point can be checked against the position of the dial on the scale of the measuring apparatus. At the same time, the electrodes for the electrocardiogram are applied, and in a number of cases, for reference, heart sounds are simultaneously recorded elsewhere on the chest wall.

It must be borne in mind that the mass of the heart-sound microphone may influence recording when an attempt is made to derive both phenomena too close together, with the measuring apparatus in a sensitive measuring position.

We carried out recordings with the patient in deep expiration, holding his breath.

\section{Results}

Fig. 3 shows the sites on the precordium, and elsewhere, at which we recorded precordial movements or their derivations.

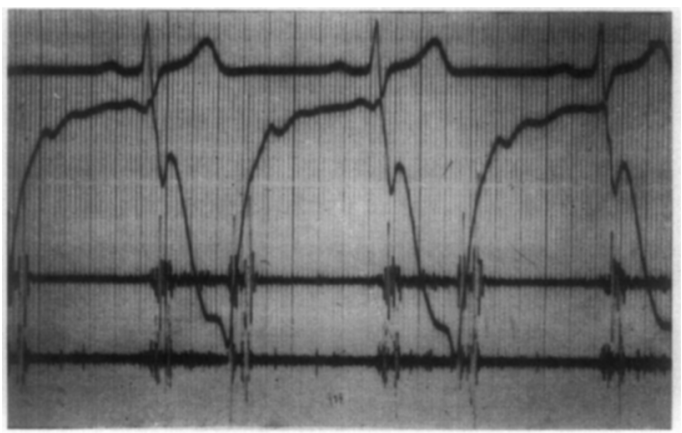

Fig. 9. Kinetocardiogram: $(4 \mathrm{~L} 1)=\mathrm{K}_{24}$. Measuring range: $+30 \mu \mathrm{m}$ to $-30 \mu \mathrm{m}$. ECG: Lead II. Phonocardiogram: Sounds 2L1. Speed of paper: $50 \mathrm{~mm}$. per second.

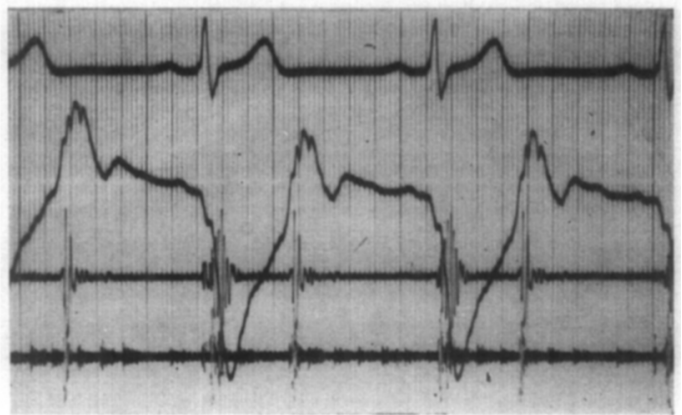

Fig. 10. Kinetocardiogram: (2L4) $=\mathrm{K}_{32}$. Measuring range, ECG, phonocardiogram, and paper speed are the same as for Fig. 7 . 
Wherever these sites corresponded with those also used by Eddleman, we inserted the Eddleman designations of $\mathrm{K}$ (kinetocardiogram) with corresponding numeral.

Obviously, the small integrating surface



Fig. 11. Kinetocardiogram: $(3 \mathrm{~L} 4)=\mathrm{K}_{33}$. Curve obtained proves ictus of right ventricle. Measuring range: $+30 \mu \mathrm{m}$ to $-30 \mu \mathrm{m}$. ECG: Lead II. Phonocardiogram: Sounds 2R1. Speed of paper: $50 \mathrm{~mm}$. per second

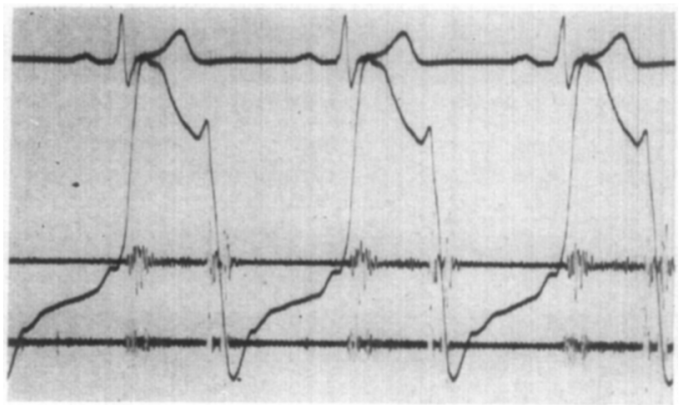

Fig. 12. Kinetocardiogram: Left ictus, dorsal recumbent position. Measuring range: $+50 \mu \mathrm{m}$ to $-\mathbf{5 0} \mu \mathrm{m}$. ECG: Lead II. Phonocardiogram: 2R1. Speed of paper: $50 \mathrm{~mm}$. per second.

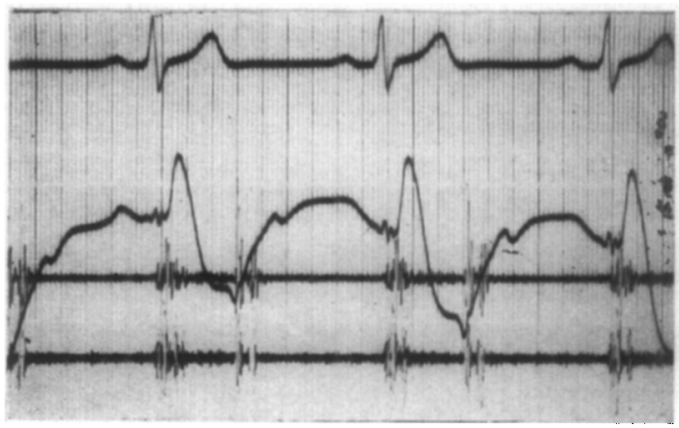

Fig. 13. Kinetocardiogram: $\mathrm{K}_{34}$. Measuring range, ECG, phonocardiogram, and paper speed are the same as for Fig. 11. of the transolucer makes it possible to enlarge the field of derivation points at will and explore the entire precordium in this manner, which ensures excellent curves illustrating the course.

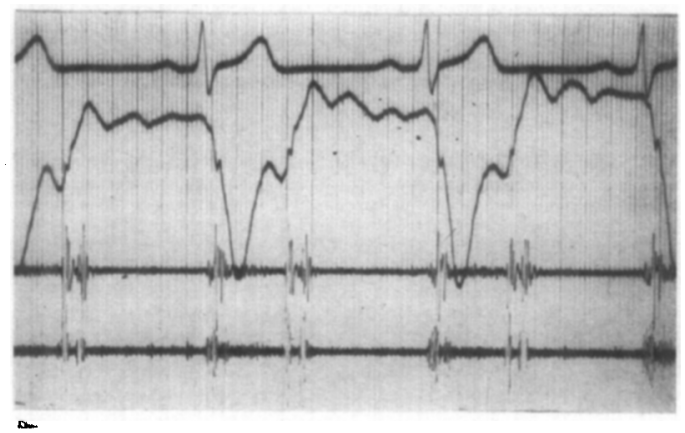

Fig. 14. Kinetocardiogram: $\mathrm{K}_{54}$. Measuring range: $+10 \mu \mathrm{m}$ to $-10 \mu \mathrm{m}$. ECG: Lead II. Phonocardiogram: Sounds 2L1. Speed of paper: $50 \mathrm{~mm}$. per second.

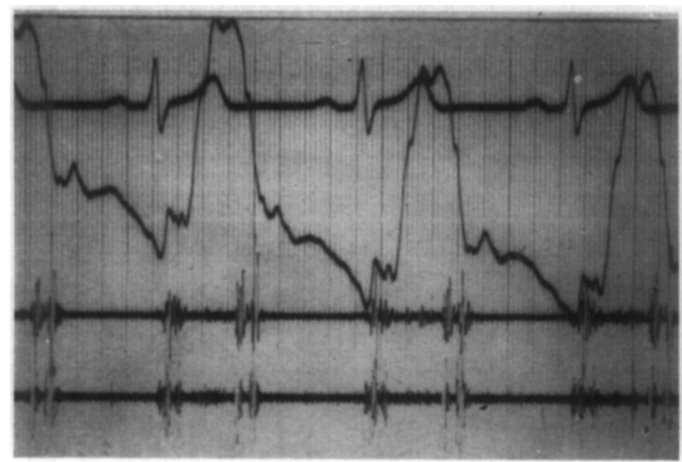

Fig. 15. Kinetocardiogram: $\mathrm{K}$ ensiform. Measuring range, ECG, phonocardiogram, and paper speed are the same as for Fig. 14.

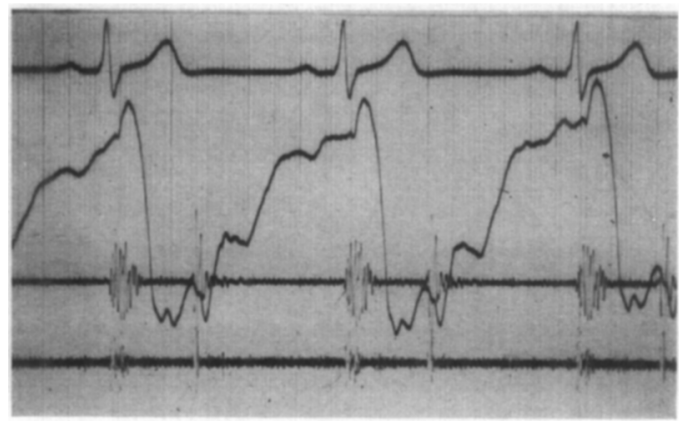

Fig. 16. Kinetocardiogram: Mid-clavicular 1R epigastrium. Measuring range, ECG, phonocardiogram, and paper speed are the same as for Fig. 14. 
Figs. 4 through 16 present a few results obtained by this method of registration in a 13-year-old male patient.

A detailed discussion or explanation of the illustrations is not within the scope of this paper.

\section{Summary}

1. A description is given of a new method of recording precordial movements of the chest wall, with illustrations depicting the apparatus and the mode of application to the subject to be examined. A number of curves obtained by this method are presented in addition.

2. The authors believe that the new method offers the following advantages over conventional recording methods: (a) small integrating surface of the transducer, as a result of which precordial displacements of the chest wall are locally measured, whereas other transducers measure a contribution from several precordial sites; (b) proportional and reproducible recording of precordial displacements caused by the heart action; (c) instant registration, frequency range, and high sensitivity because of the pliysical characteristics of the transducer and the measuring apparatus.

3. Results and interpretations obtained from hearts with a normal and a pathophysiologic function will be presented in a subsequent publication.

\section{REFERENCES}

1. Crehore, A.: Study of tracings from region near apex of heart, J. Exper. Med. 14:351, 1911.
2. Weitz, W.: Über die Kardiographie am gesunden Herz mit dem Frankschen Apparat. Über die Kardiographie des pathologischen Herzens mit dem Frankschen Apparat, Deutsch. Arch. klin. Med. 124:134 and 155, 1917.

3. Wiggers C. J.: Circulation in health and disease, Philadelphia, 1923, Lea \& Febiger.

4. Dressler, W.: Die Brustwandpulsationen als Symptome von Herz- und Gefässkrankheiten, Vienna, 1933, Verlag Wilhelm Maudrich.

5. Rappaport, M. B., and Sprague, H.: The graphic registration of the normal heart sounds, AM. HeART J. 23:591, 1942.

6. Johnston, F. D., and Overy, D. C.: Vibration of low frequency over the precordium, Circulation $3: 579,1951$.

7. Luisada, A., and Magri, G.: The low-frequency tracings of the precordium and epigastrium in normal subjects and cardiac patients, AM. HEART J. 44:545, 1952.

8. Eddleman, E. E., Jr., Willis, K., Reeves, T. J., and Harrison, T. R.: The kinetocardiogram. Method of recording precordial movements, Circulation 8:269, 1953.

9. Eddleman, E. E., Jr., Willis, K., Christianson, L., Pierce, J. R., and Walker, R. R.: The kinetocardiogram. The normal configuration and amplitude, Circulation 8:370, 1953.

10. Eddleman, E. E., Jr., and Willis, K.: The kinetocardiogram. The distribution of forces over the anterior chest, Circulation 8:569, 1953.

11. Groom, D., and Boone, J. A.: The recording of heart sounds and vibrations. II. The application of an electronic pick-up in the graphic recording of subaudible and audible frequencies. Exper. Med. \& Surg. 14:255, 1956.

12. Eddlcman, E. E., Jr., Hefner, L., Reeves, T. J., and Harrison, T. R.: Movements and forces of the human heart. I. The genesis of the apical impulses, Arch. Internat. Med. 99:401, 1957. 